\title{
Online Speaking Strategy Assessment for Improving Speaking Ability in the Area of Language for Specific Purposes: The Case of Tourism
}

\author{
Malinee Phaiboonnugulkij ${ }^{1} \&$ Kanchana Prapphal $^{2}$ \\ ${ }^{1}$ Nakhon Ratchasima Rajabhat University, Thailand \\ ${ }^{2}$ Chulalongkorn University, Thailand \\ Correspondence: Malinee Phaiboonnugulkij, Faculty of Humanities and Social Sciences, Nakhon Ratchasima \\ Rajabhat University, 30000, Thailand. E-mail: malineerabbit@hotmail.com
}

Received: May 23, 2013 Accepted: June 7, 2013 Online Published: August 15, 2013

doi:10.5539/elt.v6n9p19 URL: http://dx.doi.org/10.5539/elt.v6n9p19

\begin{abstract}
The purpose of this study was to compare the differences in strategies used in an online language for specific purposes (LSP) speaking test in tourism with two proficiency groups of students, and to investigate the strategies that should be used for low-proficiency students to improve their LSP speaking ability. The Web-based Speaking Test in English for Tourism (WBST-EFT) and a coding scheme were used as research instruments. Descriptive statistics, the Man-Whitney U test, percentages, and qualitative content analysis from verbal reports were used in the data analysis. The findings showed that the two proficiency groups significantly and differently reported cognitive and metacognitive strategies for this LSP online speaking test. The qualitative results indicated that high-proficiency students used more complex details in all of the sub-strategies than the low-proficiency students. Low-proficiency students should be trained to effectively employ these strategies to improve their LSP speaking ability through the use of an online LSP speaking test that has been considered as an effective tool and that provides an opportunity for students to self-assess and self-practice their performances. Both strategies and online speaking tools can be used with a large number of students to develop LSP speaking ability in tourism.
\end{abstract}

Keywords: speaking strategies, English for tourism speaking performance, language for specific purposes, online speaking test

\section{Introduction}

The tourism enterprise is one of the major sources of income for Thailand and creates approximately $6.7 \%$ of the kingdom's gross domestic product, with approximately 18.82 million tourists arriving in 2011 (Thailand Tourist Arrivals, 2011). For this reason, a large number of educational institutions offer English for Tourism courses to produce proficient English speaking staff members, particularly tour guides. Since tour guides are among the key individuals in various tourism enterprises that directly communicate with linguistically-diverse tourists, English speaking skills are essential for their chosen career.

Despite the importance of the tourism industry in the Thai economy, English for Tourism course is taught at Nakhon Ratchasima Rajabhat University (NRRU) to approximately 20,000 students. As part of the course requirements, students have to pass a test at a certain levels of English language speaking performance. A semi-direct online-mediated speaking test was purposively employed in this study to solve the administration problems at the university caused by the large number of students and because of its practical advantages. Test administration in this case is flexible, as an online speaking test is easy to construct. It is also considered cost-effective because of the free downloadable platform that is available (Garcia Laborda, 2007a). Most importantly, it provides an opportunity for students to self-assess and practice their performances (Chapelle \& Douglas, 2006). Additionally, recent studies indicate that non-native English students praise the interactive part of computer-mediated speaking tests, which can simulate real life situations, and they can use this technology on a daily basis. They also feel more comfortable taking this semi-direct speaking test than a direct speaking test (Yu, 2012). However, very few research studies have been conducted on an online speaking test (Garcia Laborda, 2007a), specifically regarding the strategies used for LSP in the tourism context.

According to Douglas (2000), English for Tourism is considered to be one area of language for specific purposes (LSP). This classification is from the utilization of English for a particular purpose in a targeted setting. 
Following Douglas's views (2000), LSP ability is a result of the interaction between specific purpose background knowledge and language ability in which strategic competence acts as mediator between language knowledge and background knowledge and test input. Strategic competence is made up of four strategies namely, discourse assessment, communicative goal setting, linguistic planning, and control of linguistic execution. Strategic competence is thus significant in LSP ability utilized in speech production. An analysis of strategic competence can provide details that we can anticipate from students' performances (Fulcher, 2003a). Moreover, a number of research studies have claimed that successful learners employ a particular type of strategy in their communication (Swain, Huang, Barkaoui, Brooks \& Lapkin, 2009; Lam, W.Y.K., 2007; Nakatani, 2006).

Considering the significant role of strategic competence in LSP ability, and the scant number of research studies on strategies used in LSP online-mediated speaking tests in tourism, there is a strong need to investigate the strategies used in this test modality, especially for pedagogical purposes. The goal is to assist the large number of low-proficiency students to effectively improve their LSP speaking ability. The findings on the strategies used in the LSP test for the present study will provide fruitful information in designing course contents and instructional approaches that facilitate the use of these strategies in English for Tourism courses in the context of Thailand. Additionally, an LSP online speaking test could be implemented in other LSP courses at NRRU to a large number of students. This study, thus, aims to compare the types and frequencies of speaking strategies used by high- and low-proficiency students, and to investigate the strategies that should be trained for low-proficiency students, to improve their LSP speaking ability in the area of tourism.

\section{Literature Review}

\subsection{Speaking Strategy Taxonomy}

Following the interactional view of the language competence model (Bachman \& Palmer, 1996), Fulcher (2003a) notes that the strategies used in speaking were derived from analysis of strategic competence, which "provides details of what we could look for in test-takers' speech" (p.31). He also states that the strategies used in speaking comprise two main categories: achievement and avoidance. Achievement strategies are used when learners lack knowledge of the target language, particularly regarding lexicon and grammar. Therefore, they try to overcome this difficulty by finding a way around the problem. This category includes six strategies: overgeneralization/morphological creativity, approximation, paraphrase, word coinage, restructuring, and code switching. Avoidance (or reduction) strategies, on the other hand, are used when learners do not have full control of the target language. This category of strategies has been used mostly by low-proficiency learners (Littlemore, 2003). Avoidance strategies are made up of formal and functional avoidance. Formal avoidance occurs when learners avoid using a particular part of the language system. However, this strategy is difficult to detect. Learners use functional avoidance to avoid a particular word, topic, or to end the conversation.

For the present study, the speaking strategy was derived from reported behaviors or thoughts during the test-taking process. Theoretically, Swain et al. (2009) states that test-taking strategies are "the conscious, goal-oriented thoughts and behaviors test-takers use to regulate cognitive processes, with the goal of improving their language use or test performance" (p.2). Therefore, the speaking strategies in this study incorporate mixed frameworks and are comprised of communication strategies (achievement and avoidance strategies), cognitive strategies (selecting, comprehending, storing memory and retrieval), and metacognitive strategies (goal setting, organizing, planning and evaluating) (Fulcher, 2003a; Bachman \& Palmer, 1996; Swain et al., 2009).

\subsection{Strategic Competence in LSP Ability}

According to Douglas (2000), language for specific purposes (LSP) ability "results from the interaction between specific purpose background knowledge and language ability, by means of strategic competence engaged by specific purpose input in the form of test method characteristics" (p.40). Douglas's definition of LSP ability is based on Bachman and Palmer's (1996) model of communicative language ability, with some modification of the strategic competence component, and he added the notion of background knowledge to the model. In a specific purposes context, the relationship between language ability and specific background knowledge is one of the key features of LSP.

The LSP ability model is comprised of three factors: language knowledge, strategic competence, and background knowledge. Language knowledge incorporates grammatical knowledge, textual knowledge, functional knowledge, and sociolinguistic knowledge. Language knowledge deals with the process of language production and its appropriate use in context situations. Strategic competence refers to the metacognitive strategies or higher order thinking and communication strategies which are hierarchically employed by language users. Background knowledge is the central issue that marks distinctive characteristics of LSP ability. Individuals relate this long term memory knowledge, which is based on previous experience, with the present input to predict upcoming 
events and to make a decision. In the testing context, test-takers retrieve pertinent background knowledge and relate it with language knowledge to interpret the communicative situation and to respond to the test tasks that resemble the target language use situation. Strategic competence serves as the mediator to facilitate the interaction between these language ability components. In Douglas' LSP ability framework, strategic competence consists of discourse assessment, communicative goal setting, linguistic planning, and control of linguistic execution.

There are few studies that have investigated the inclusion of strategic competence in the LSP construct, as indicated by Elder (2001). The author reported the mismatch of the test-takers' LSP communicative ability between linguistic competence and non-language ability, such as strategic competence and teaching skills. Elder proposed that linguistic ability should be separated from non-language competence. This approach of separating these factors could be employed in situations when assessing the sensitivity of contextual situational English usage and can be substituted for inadequate linguistic competence.

\subsection{Strategies Used in Language Performance}

Research on the strategies used in language performance, particularly speaking ability, has been conducted on the comparison of proficiency levels and strategies used with varied results. Although participants employed a wide array of strategies, only some strategies had positive effects on language performance (Song, 2005). This includes the interaction between the strategy used and the level of proficiency; however, the findings remain inconclusive (Nakatami, 2006; Ting \& Phan, 2008; Cabaysa \& Baetiong, 2010; Ma, 2009; Mendez Lopez, 2011; Anderson, 1983 cited in Van Moere, 2006).

A study conducted by Song (2005) explored the language strategy used in the Michigan English Language Assessment Battery (MELAB) and the relationship between the strategy used and learners' performance. A total of 179 students that took the MELAB participated in this experiment. Questionnaires on the strategies used, focusing on cognitive and metacognitive strategies, were distributed to obtain data on the reported strategies. The findings revealed that the students used six types of cognitive strategies: repeating/confirming information strategies, writing, practicing, generating, applying rules, and linking with prior knowledge. They also used three metacognitive strategies: evaluating, monitoring and assessing. The analysis indicated that the more test-takers synthesized what they had learned and applied it in actual practice, they performed better. In contrast, the use of repetition strategies led to worse performance. Similarly, the finding of Nakatani (2006) corresponds with previous studies (Song, 2005). This author investigated learners' strategies used in communication tasks as part of the validation study of the oral Communication Strategy Inventory questionnaire (OCSI). A comparison of the strategies used across proficiency levels was conducted and the findings showed that some strategies were favored by a particular proficiency group. Sixty-two Japanese female students were selected to participate in the study and were separated into high, middle, and low-proficiency groups using the Oral Test Assessment Scale for Japanese ESL. It was found that social-affective strategies, fluency-oriented strategies, and negotiation for meaning were used more by the high-proficiency group than the low-proficiency one.

Moreover, Cabaysa and Baetiong (2010) compared the frequency and types of language learning strategies of intermediate and novice students. The authors found that the two ability groups reported using metacognitive, social/affective, and compensation strategies. There was a significant difference in the frequency of the metacognitive strategies between the two groups (Novice $=75$, Intermediate $=165$ ). The intermediate group reported more than twice as many metacognitive strategies as the novice group. Ma (2009) conducted an empirical study on the comparison between strategies employed in oral English classes and writing classes. Cognitive, metacognitive, and social and affective strategies were investigated. As part of the study, it was found that proficiency levels were significantly and closely correlated with the use of speaking strategies. Students with high proficiency levels tended to employ more language strategies than those with low proficiency levels.

Similarly, these findings correspond with the recent findings of Mendez Lopez (2011). The authors investigated the speaking strategies used by bachelor's degree English language teaching students from five public universities in Mexico, which were categorized into beginner, intermediate, and advanced groups. The strategies included asking for repetition, paraphrasing, and asking for message clarification. It was found that asking for message clarification was the most reported strategy out of the three proficiency groups. More specifically, students selected strategies in relation to their proficiency levels. Beginners used speaking strategies to compensate for the lack of language knowledge, whereas intermediate students were more likely to make use of their background knowledge; thus, this group reported the most varied strategies among the three groups. These findings agreed with the results from a study of cognitive development by Anderson (1983, cited in Van Moere, 2006), in that a particular proficiency group benefited from a particular strategy. The author indicated that the 
mastery of the target language linguistic knowledge facilitated the candidates' cognitive processing resources so that they were to effectively produce speech. For this reason, the high-proficiency candidates may have an advantage from their cognitive processing as they had to spend less time on input processing and response formulation than the low-ability candidates.

Contrastively, Ting and Phan (2008) found no difference in the total number of strategies used in an oral simulated discussion task across EFL learners' proficiency levels. The authors investigated the influence of the target language proficiency of EFL learners and interlocutors on the use of communication strategies with 20 undergraduate Malaysian participants. They were separated into proficient and less proficient groups according to their Malaysian University English Test (MUET) scores. The findings showed that the proficient group employed 132 individual strategies, whereas the less proficient group used 142 strategies. Thus, the statistical data revealed no difference in the total number of strategies used.

\subsection{Strategies Used in Web-Based/Computer-Based Speaking Performance}

A number of research studies on technology-integrated speaking performance have shown that examinees employ a wide range of strategies to attempt the test tasks (Swain et al., 2009; Smith, 2003). Some studies focused on the communication strategies used (Smith, 2003), whereas some included particular strategies used in a certain task types (Swain et al., 2009; Smith, 2003). The findings regarding students' choices of strategies used in a particular task type remain inconclusive (Swain et al., 2009).

Swain et al. (2009) investigated the strategies used for the Internet-based TOEFL, focusing on the speaking section, across the three task types: 1) independent, 2) integrated reading, listening and speaking, and 3) integrated listening and speaking. The relationship between the reported strategies and participants' performance on the task based on their test scores was examined. The participants were 16 graduate and 14 undergraduate Chinese speakers, separated into four proficiency levels according to their language proficiency pre-test scores: graduate advanced (A), graduate intermediate (B), undergraduate advanced (C), and undergraduate intermediate (D). A background questionnaire was distributed to all participants before the administration of the speaking section of the TOEFL iBT (SSTiBT). The findings showed that the participants used overall 49 individual strategies across six tasks, which were categorized into five types: metacognitive, communication, cognitive, approach, and affective. Metacognitive (33.42\%), communication $(26.48 \%)$, and cognitive $(25.04 \%)$ were reported as the three most frequently-used strategies. Regarding the strategies used and proficiency levels, communication strategies were significantly used more by undergraduates, particularly in the organizing thought strategy. Contrastively, graduates significantly employed more cognitive and affective strategies than undergraduates. The results of the study indicated no statistically significant differences in the strategies used between two proficiency groups.

Likewise, the strategies used in the computer-mediated context were investigated by the Smith (2003). The focus of the study was on communication strategies for maintaining discourse or conversation, as well as compensation, strategies used to compensate for the lack of target language knowledge. The effects of task types on the strategies used and the effectiveness of particular communication strategies were also explored. The participants were comprised of 18 intermediate ESL students in U.S. universities with diverse L1 backgrounds. They were required to participate in a pair task in a computer-mediated communication environment (CMC) called ChatNet, a software program used for typing message to communicate for 5 weeks. It was found that the participants used a wide range of communication strategies during their CMC task performance. The four most frequently used out of 26 strategies were: fillers (54 times), substitutions (43 times), framing (30 times), and politeness (28 times). The present study found no task effects on communication strategies; however, the task types might affect the use of compensation strategies. Almost twice as many compensation strategies were used in the decision-making tasks (65\%) compared to those of the jigsaw tasks (35\%).

\subsection{Advantages and Disadvantages of Technology-Mediated Oral Proficiency Performance}

Due to the number of their technological advantages concerning test construction and administration, web-based language tests (WBT) have been increasingly used in testing contexts (Roever, 2001). Web-based language tests share similar features with computer-based language tests (CBT). Two advantages of the WBT testing approach over a CBT testing approach are their flexibility and convenience in test administration (Roever, 2001). According to Hamilton, Klein, and Lorie (2000), and Roever (2001), WBT has gained status in the assessment context arising from its being very user-friendly. This is especially true regarding a low-tech approach that does not require expertise in programming or sophisticated hardware or software. Internet technology also allows test developers to create interactive, semi-direct speaking tests due to the availability of free software and the capability to post tests online for free; hence, the test is considered to be cost-effective. The low-tech WBT was 
an integral part of this study due to its practicality in being a user-friendly program, less dependent on technology expertise, and because of the reduced financial concerns regarding test development.

Few studies have claimed that the WBT is suitable for low-stakes assessment (Chapelle \& Douglas, 2006; Roever, 2001), especially for self-assessment. However, Garcia Laborda (2007a) wrote on the use of the World Wide Web platform for standardized high-stakes tests. He projected that numerous standardized technology-based tests will eventually be available online and will include speaking skill evaluation. Likewise, Hamilton et al. (2000) discussed the feasibility of using WBT for large-scale standardized tests due to its numerous technological advantages, such as being inexpensive, its rapid scoring capability, the central storage of item banks, and its being less dependent on sophisticated software and hardware. All of these attributes of WBT makes it suitable for large-scale testing projects. One of the most prominent standardized tests is the Test of English as a Foreign Language (TOEFL iBT), which incorporates online technology in test delivery and administration, specifically in the speaking section (Alderson, 2009). A recent study of Yu (2012) with 208 non-native English speakers in the U.S. showed that the participants preferred the computerized version of the SPEAK test over audio-tape oral proficiency tests, although the most preferred modality was the direct face-to-face interview. Participants praised the computerized modality speaking test on its interactive technology, which could simulate the real life situation of video conferencing. They felt more comfortable taking the computerized speaking test than using the audio-tape modality because they use computers on a daily basis and they also claimed that the standardized procedures in the computerized mode would assess their speaking ability more accurately than the interview test. However, the participants mentioned the disadvantages of computer-based speaking test - that this modality did not allow two-way dynamic interaction and there was no second chance for clarification; therefore, the author suggested that both timers and tutorials should be used to solve these problems.

Although these previous studies reported on the use of Internet technology in a number of skill areas, its use is limited regarding speaking ability, as claimed by Garcia Laborda (2007a), particularly in the LSP context, which is the focus of the present study. Therefore, this study aims to compare types and frequencies of speaking strategies used by high- and low-proficiency students in taking the WBT-EFT, and investigate the strategies that should be trained for low-proficiency students to improve their LSP speaking ability. The research questions have been formulated for these objectives as follows: "Are there any differences in speaking strategies used by high- and low-proficiency students in attempting the WBT-EFT?", and "What are the strategies that students need to be trained to improve their LSP speaking ability?"

\section{Methodology}

\subsection{Participants}

The sample group was 120 participants that had an English for Tourism I (EFT I) course grade of A, B+, B and D; they were randomly selected to participate in this study. They were then classified into two groups based on their EFT I course grade. The mean score of the EFT I course grade was 67.50 and the standard deviations were 10.16. The $Z$ value was calculated to categorize the participants into the high- and low-proficiency groups. The 60 participants that had the highest $Z$ scores were assigned into the high-proficiency group ( $Z=0.3$ to 1.5 ) and the 60 participants with the lowest $Z$ scores were categorized as the low-proficiency group $(Z=-0.5$ to -1.7$)$. Then, nine participants from each proficiency groups for a total of 18 were randomly selected to participate in the stimulated recall interview session to elicit the types and frequency of strategies used in doing the test.

\subsection{Research Instruments}

\subsubsection{The Web-Based Speaking Test in English for Tourism (WBST-EFT) and the Rating Scale}

The WBST-EFT was developed under the theoretical framework of the LSP test development proposed by Douglas (2000), which had been modified from the framework of Bachman and Palmer (1996). This instrument also included the interface design framework for the technology-integrated test from Fulcher (2003a). The WBST-EFT is the LSP semi-direct final achievement speaking test for English for Tourism II course at Nakhon Ratchasima Rajabhat University (NRRU). The test task contents were based on the results of the needs analysis questionnaire. Subject specialists have suggested including all of the specific features of an LSP situation in the test tasks so that these test tasks authentically share significant features of real-world tasks (Douglas, 2000). Consequently, this representation of the test performance is likely to be similar to that of the actual performance in the target situation. Some parts of the task contents were based on the analysis of the English for Tourism II course syllabus.

After the classification and selection of test tasks, the blueprint of the test was drafted. There were three sections 
in the WBST-EFT, which was categorized by task types based on the situations and language functions that were performed in the professional tour guides' career. In task type one, presenting tourist attractions tasks were pertinent to the language function in expressing tourism content knowledge. For task type two, giving polite suggestions to the tourists' tasks were related to the language functions used for making requests, suggestions, greetings, and apologizing. In this study, this task type focused mainly on making suggestions to the tourists, particularly on Thai etiquette. For task type three, the language functions dealt with tourists' enquiries and complaint tasks. Each task type was made up of two sub-tasks and there were six sub-tasks in total.

Then, all of the tasks were posted on the Moodle Version 1.9.5, which is a freeware online template and program that is currently used at NRRU. The test was administered in the computer lab. At this stage, before the rating scale was developed, the construct to be measured was obtained from the course objectives analysis using the specific purpose language ability framework of Douglas (2000) and speaking ability of Fulcher (2003b).

The Rating Scale

An analytic rating scale was used in this study due to its appropriateness for the test purpose, and it allowed for assessing specific components of language ability. In terms of criteria for correctness, accuracy in linguistic elements, range, complexity, and appropriateness of speech production were used. The rating scale consisted of seven components: knowledge of pronunciation, knowledge of vocabulary, knowledge of grammar, knowledge of language functions, knowledge of cohesion, fluency, and content knowledge. There were five ability bands for each component, starting from band level 0 (a very poor user), 1(beginner), 2 (a fair user), 3 (a good user) to 4 (a very good user). The ability band level was obtained from the summation of the averaged scores from the two raters in each test task.

\subsubsection{The Strategies Coding Scheme}

The coding scheme was developed from the list of strategies used, according to compilation of the related literature on strategic competence and Internet-based speaking test-taking strategies (Fulcher, 2003a; Bachman \& Palmer, 1996; Cohen, 1998; Cohen, 2006; Swain et al., 2009). It consisted of three main types of strategies: communication strategy (achievement and avoidance), cognitive strategy (selecting, comprehending, storing memory and retrieval), and metacognitive strategy (goal setting, organizing, planning and evaluating). After the list had been developed, the interview questions were drafted. These interview questions were employed to investigate the types and frequency of test-taking strategies used in completing the WBST-EFT. The interview included the scripts and questions used during the stimulated recall session to elicit the test-taking strategies. Similar to other instruments, the list of strategies used and the interview questions were validated by three experts in the field using the IOC table. All of the items on the list, scripts, and interview questions had an IOC value of 1.00. Similar to the previous instruments, the instructions on the interview questions and scripts were revised for clarity of language based on the experts' suggestions before the pilot and main study were conducted. The reported strategies were transcribed and categorized by two coders to avoid inconsistency and bias of the data. One of the coders was the researcher and the other one was an English lecturer that had an M.A.in Applied Linguistics with 35 years of experience in the profession.

\subsection{Data Collection Procedures}

The WBST-EFT was administered to 120 participants and after they completed the test, 18 participants from two proficiency groups were randomly selected to participate in the stimulated recall interview session to elicit the strategies used.

In the stimulated recall interview session, participants were asked to watch the playback video clips of their recorded performances when they attempted the test. They were asked to report on their thoughts before, during, and after the task performance. They could pause the clips any time they wanted while giving a report on the strategies used. Their verbal report responses were transcribed and coded by two coders. In order to ensure reliability, the coders were trained to understand the strategy taxonomy and coding procedure before the pilot study. The two coders first used the coding scheme with six sample speeches before they started coding the actual test-taking strategies responses. When there was a discrepancy of the types and frequencies of reported strategies between the two coders, the third coder was consulted in order to come to a final agreement based on the coding scheme. Some parts of the coding scheme were revised before being used in the main study.

\subsection{Data Analysis Procedures}

To answer the first research question, a Mann-Whitney U test was employed to calculate the frequencies of reported strategies from the coding scheme to identify the differences in reported strategies between the two proficiency groups. 
To answer the second research question, the frequencies of the strategies used by the low-proficiency students and an in-depth qualitative content analysis were employed to transcribe and code the data to investigate the strategies that the low-proficiency students needed to be trained in order to improve their LSP speaking ability.

\section{Results and Discussion}

\subsection{Differences in Reported Strategies between the Two Proficiency Groups}

The results from the Mann-Whitney $U$ test showed a significant difference between the two proficiency groups in both cognitive strategies $(\mathrm{z}=-2.8, \mathrm{p}<.05)$ and metacognitive strategies $(\mathrm{z}=-3.08, \mathrm{p}<.05)$, indicating that the two proficiency groups significantly and differently used these two strategies. The high-proficiency group reported more than twice as many cognitive strategies as the low-proficiency group $(\mathrm{H}=33 \%, \mathrm{~L}=21 \%)$. Similarly, the high-proficiency group reported almost twice as many metacognitive strategies as the low- proficiency group ( $\mathrm{H}=19 \%, \mathrm{~L}=10 \%)$.

As regards the sub-categories in the individual strategy, the results from the Mann-Whitney $U$ test also indicated a significant difference among the six reported strategies between the two proficiency groups, selecting, $\mathrm{z}=-2.99$, $\mathrm{p}>.05,(\mathrm{H}=6.41 \%, \mathrm{~L}=2.28 \%)$, retrieval, $\mathrm{z}=-3.33, \mathrm{p}>.05,(\mathrm{H}=9.98 \%, \mathrm{~L}=2.26 \%)$, goal setting, $\mathrm{z}=-2.65, \mathrm{p}>.05$, $(\mathrm{H}=5.70 \%, \mathrm{~L}=1.90 \%)$, planning, $\mathrm{z}=-3.17, \mathrm{p}>.05, \quad(\mathrm{H}=7.22 \%, \mathrm{~L}=3.80 \%)$, approximation, $\mathrm{z}=-2.55, \mathrm{p}>.05$, $(\mathrm{L}=1.90 \%)$, and restructuring, $\mathrm{z}=-2.20, \mathrm{p}>.05,(\mathrm{H}=1.52 \%)$.

The results show that the high-proficiency group outnumbers low-proficiency group in five strategies except the approximation strategy. Approximation was only used by the low-proficiency group to substitute the technical terms with more generic terms; this might be due to the limited lexicons of the low-proficiency group. Additionally, restructuring was solely employed by the high-proficiency group to solve the target language difficulties and to continue their responses, while the low-proficiency group would abandon the conversation.

The findings correspond with the studies of Song (2005) and Cabaysa and Baetiong (2010). The study of Cabaysa and Baetiong (2010) found a significant difference in the frequency of strategies used by the students of different levels of speaking proficiency, particularly in the use of metacognitive strategies. Similarly, the choices of strategy used by a particular proficiency group were also found in a recent study of Mendez Lopez (2011) in that the high-proficiency learners reported more complex speaking strategies than the lower-level language learners.

\subsection{Strategies that Students Should Be Trained in to Improve Their LSP Speaking Ability}

The results from 4.1 indicate that the two proficiency groups significantly and differently reported six strategies, and five of them were mainly reported by high-proficiency students. Therefore, the low-proficiency students need to be trained in these strategies of selecting, retrieval, goal setting, planning, and restructuring.

These findings are pertinent to previous study of Swain et al. (2009) on the speaking strategies used in the Internet-based TOEFL. The findings showed that a particular type of strategy was associated with the proficiency levels. Communication strategies were employed more by the undergraduate students than the graduate students, while the graduate students outnumbered their counterparts in cognitive and affective strategies.

In-depth details on the differences in the use of the five strategies between the high- and low-proficiency students are presented in the following qualitative content analysis from the students' verbal reports. These strategies are the five reported strategies that the low- proficiency students need to be trained in. The reports were from the 18 students in attempting the WBST-EFT, nine high-proficiency students and nine low-proficiency students. The students' identification was coded by the letter ' $\mathrm{H}$,' representing 'the High-proficiency group,' and the letter 'L,' representing 'the Low-proficiency group.' The number indicates the reporter. The brackets represent the information added by the researcher for explicit understanding of the speech, and '*' represents a strategy that was not in the taxonomy. The categorization of the strategies in this study is based on Swain et al. (2009, pp. 68-69).

\subsubsection{The Selecting or Attending Strategy}

The selecting or attending strategy was used to direct attention to a specific feature of the task.The students focused on the different and prominent parts of the test tasks. For example, high-proficiency students focused on the salient features of the pictures, the important information and key words, instructions, types of questions from tourists' speech, situations, and vocabulary and tourists' gestures. The majority of high- proficiency students mainly focused on important information from the test prompt, whereas low-proficiency students were able to only focus on the key words due to their low ability in English. Some examples are given below. 
- Focusing on important information and key words

- H3: [I] focused on the important part and answered in my own words [To explain] Wat Phra Kaew [the Emerald Buddha Temple], [I] used "This is the Emerald Buddha Temple."

- L1: [I] listened carefully to the vocabulary. [Tourists] spoke too fast [and I] could not catch up.

\subsubsection{The Retrieval Strategy}

The retrieval strategy was used to retrieve L2 linguistic resource and background knowledge to attempt the test tasks. This included recombining the target language knowledge, transferring L1 linguistic knowledge, translating L1 to L2, recalling, *remembering L2 linguistic knowledge and *using pictures to recall L2 linguistic knowledge. Almost all of the sub-strategies were mainly reported by high-proficiency students, and they primarily relied on their L2 knowledge. In contrast, the low-proficiency students depended on their L1 linguistic knowledge as could be seen from transferring their L1 linguistic knowledge, which was only reported by this group of students. Some examples are presented below.

- Remembering L2 linguistic knowledge

- H4: [I] thought of important L2 structures. For example, [I] wanted to warn the tourists to keep their wallet [so I] needed to translated some parts in Thai and translated back into L2 as "Please [be] careful for your wallet."

\section{- Transferring L1 linguistic knowledge}

- L3: [I] sometimes used Thai grammar to construct sentences.

\subsubsection{The Goal Setting Strategy}

The goal setting strategy involved identifying the tasks and deciding what to do. In this strategy, the students identified the different parts of the tasks before organizing their thoughts to respond to the tasks. Similar to the previous strategies, the goal setting strategy was primarily reported by the high-proficiency group. High-proficiency students identified the information in the tasks and in the prompt, organized their thoughts, and thought of the reason for responding to the task. However, the low-proficiency students mainly focused on the information in the task and directly formulated their answer. Following are some examples.

- Identifying the information in the tasks and deciding what to do

- H2: For example, with the picture or tour program [I] needed to understand first and decided on what to do.

- H8: [I] listened and [tried to] understand [the conversation]. For example [in the] complaint [situation I] needed to apologize first and then tried to find the supporting reason to respond [to the task].

- L7: [I] found out on what the tourists wanted to prepare the answer.

\subsubsection{The Planning Strategy}

The planning strategy dealt with deciding how to use existing linguistic knowledge and background tourism knowledge to respond to the test task. High-proficiency students decided to use their tourism knowledge that was relevant to the prompt and situations; they also used their linguistic knowledge by organizing the existing grammatical sentence structures and vocabulary to respond to the task. However, the low-proficiency students mainly used their knowledge of tourism that they had learned from the class and directly formulated their answer. Examples of the sub-strategy are listed below.

- Organizing grammatical sentence structures and background knowledge related to prompts

- H1: [I] thought of how to use the tourism information to respond [to] the prompt. And which structures should be used?

- H2: Yes, I needed to use tourism knowledge to respond to the task. But, if I struggled, I put my opinions especially for the recommendation for the tourists. Then, I think of grammatical structures.

- L5: [I] tried to think of how to use the tourism information from the class to warn the tourists. [I] focused on Thai cultural information on prohibition. Then, [I] made sentences.

\subsubsection{The Restructuring Strategy}

The restructuring strategy was employed in the case when the students used different structures to convey the similar meaning of the message and most of the time they substituted less complex structures with more complex ones. This strategy was only used by the high-proficiency students. For instance,

- H8: [I] used easy sentences that [I] could think of to answer [the question]. 
- H9: [I] used the closest meaning sentence like "Sorry sir, I hope it's not [doesn't] happen again" for "I'm sorry sir I won't let it happen again."

\section{Conclusion and Implications}

This study aimed to compare the types and frequencies of speaking strategies used by high- and low-proficiency students in attempting the WBT-EFT, and to investigate the strategies in which low-proficiency students should be trained in order to improve their LSP speaking ability. The findings showed that the high-proficiency students significantly reported higher frequencies of cognitive and metacognitive strategies than the low-proficiency students. Further, the results from the qualitative analysis showed that the high-proficiency students used more complex details in all of the sub-strategies than did the low-proficiency students. The high-proficiency students also primarily relied on their L2 linguistic knowledge to respond to the test task, whereas the low-proficiency students depended mostly on their L1 linguistic knowledge. The low-proficiency students should be trained to effectively employ these strategies to improve their LSP speaking ability.

Since LSP has precise characteristics of language use in a particular situation and in particular test tasks, and strategic competence or metacognitive strategies are hierarchically used in LSP ability (Douglas, 2000), LSP instructors should therefore train low-proficiency students in how to effectively use these strategies to improve their LSP speaking ability. Additionally, these strategies should be emphasized in English for Tourism course instructional methods and course content design. To be precise, lecturers could prepare low-proficiency students to set their goals before they actually attempt the test task by identifying the information from both the instruction and the prompt in the test task before organizing their responses. Then, they should plan their responses by thinking about how to use their tourism content knowledge that was related to the test task; and most importantly they should think about how to organize the L2 grammatical structures and vocabulary in their answer. They should also use the selecting strategy by focusing on the information from both the directions of the test task and the situation in the prompt, including the key words in the test. They also should be instructed to effectively use the retrieval strategy by thinking directly about the L2 grammatical structures that are related to the test task. Finally, they should be trained to restructure their answers by using different grammatical structures to formulate their responses. They should be informed that it is better to use easy structures than just skip a task without providing an answer. It was found in previous study that low-ability students just abandoned the test instead of using this strategy, whereas high-ability students tried to adjust their answers by substituting less complex structures for more complex ones (Phaiboonnugulkij, 2011).

Owing to the advantages of online technology for pedagogical purposes, low-proficiency students could use this test for self-diagnostic purposes, which has been mentioned for its suitability by a number of scholars (Chapelle \& Douglas, 2006; Roever, 2001). In this learning environment, students can assess and practice their speaking skill at their own pace due to the primary advantage of this online test regarding its logistic flexibility (Roever, 2001). Students can re-practice and re-assess themselves. On the other hand, lecturers can use this online test as an instructional instrument to train low-proficiency students to use effective strategies through this medium since it is possible to store students' responses and retrieve the data at any time. Because of its numerous technological advantages (inexpensive test construction from free downloadable programs, central storage of item banks, and less dependence on sophisticated software and hardware), an online LSP speaking test could be used in other LSP courses at NRRU to improve speaking ability for a large number of students, as well as providing them with the opportunity to learn and evaluate their own performances.

\section{Acknowledgements}

The author would like to thank the Office of the Higher Education Commission, Thailand, according to the Strategic Network Project for Production and Development of High Educational Institution Instructors in the Domestic Doctoral Degree Program, for their financial support in conducting this study.

\section{References}

Alderson, J. C. (2009). Test review: Test of English as a Foreign Language TM: Internet-based test (TOEFL iBT). Language Testing, 26(4), 621-631. http://dx.doi.org/10.1177/0265532209346371

Anderson, J. R. (1983). The architects of cognition. Cambridge, MA: Harvard University Press.

Bachman, L. F., \& Palmer, A. S. (1996). Language testing in practice. Oxford: Oxford University Press.

Douglas, D. (2000). Assessing languages for specific purposes. Cambridge: Cambridge University Press.

Cabaysa, C. C., \& Baetiong, L. R. (2010). Language learning strategies of students at different levels of speaking proficiency. Education Quarterly, 68(1), 16-35. 
Chapelle, C. A., \& Douglas, D. (2006). Assessing language through computer technology. Cambridge: Cambridge University Press.

Cohen, A. D. (1998). Strategies in learning and using second language. New York: Addison Wesley Longman Limited.

Cohen, A. D. (2006). The coming age of research on test-taking strategies. Language Assessment Quarterly, 3(4), 307-331. http://dx.doi.org/10.1080/15434300701333129

Elder, C. (2001). Assessing the language proficiency of teachers: are there any teacher controls? Language Testing, 18(2), 149-170. http://dx.doi.org/10.1177/026553220101800203

Fulcher, G. (2003a). Interface design in computer-based language testing. Language Testing, 20(4), 384-408. http://dx.doi.org/10.1191/02655322031t265oa

Fulcher, G. (2003b). Testing second language speaking. London: Pearson Education.

Garcia, Laborda, J. (2007a). From Fulcher to PLEVALEX: issues in interface design, Validity and reliability in internet based language testing. CALL-EJ Online, 9(1). Retrieved from http://callej.org/journal/9-1/laborda.html

Garcia, Laborda, J. (2007b). On the net: introducing standardized EFL/ESL exams. Language Learning and Technology, 11(2), 3-9.

Hamilton, L. S., Klein, S. P., \& Lorie, W. (2000). Using Web-based Testing for Large-scale Assessment. Santa Monica: RAND Corporation. Retrieved from http://www.rand.org/pubs/issue_papers/IP196.html

Lam, W. Y. K. (2007). Tapping ESL learners' problems and strategies in oral communication tasks: Insight from stimulated recall. Prospect, 22(1), 56-71.

Littlemore, J. (2003). The communicative effectiveness of different types of communication strategy. System, 31, 331-347. http://dx.doi.org/10.1016/S0346-251X(03)00046-0

Ma, T. (2009). An empirical study on the comparison between strategies on oral English classes and writing English classes. English Language Teaching, 2(2), 39-45.

Mendez, Lopez, M. (2011). Speaking strategies used by BA ELT students in public universities in Mexico. MEXTESOL Journal, 35(1), 1-22.

Nakatami, Y. (2006). Developing an oral communication strategy inventory. The Modern Language Journal, 9 , 151-168. http://dx.doi.org/10.1111/j.1540-4781.2006.00390.x

Phaiboonnugulkij, M. (2011). The Effects of Web-based Speaking Test in English for Tourism (WBST-EFT) Task Types and English Proficiency Levels on Students' Speaking Performance and an Investigation of Their Attitudes and Test Taking Strategies. (Doctoral Dissertation). Chulalongkorn University, Thailand.

Roever, C. (2001). Web-based language testing. Language Learning and Technology, 5(2), 84-94.

Smith, B. (2003). The use of communication strategies in computer-mediated communication. System, 31, 29-53. http://dx.doi.org/10.1016/S0346-251X(02)00072-6

Song, X. (2005). Language learner strategy use and English proficiency on the Michigan English Language Assessment Battery. Spaan Fellow Working Papers in Second or Foreign Language Assessment, 3, 1-26.

Swain, M, Huang, L., Barkaoui, K., Brooks, L., \& Lapkin, S. (2009). Educational Testing Service (ETS). The speaking section of the TOEFL iBT (SSTiBT): Test-takers' reported strategic behaviors (TOEFL iBT Research Report No.10). Retrieved from http://www.ets.org/Media/Research/pdf/RR-09-30.pdf

Thailand, Tourist, Arrivals. (2011). Thailand Tourist Arrivals from 2007 to 2011 Per Quarter. Retrieved from $\mathrm{http}: / / \mathrm{www}$.thaiwebsite.com/tourism.asp

Ting, S., \& Phan, G. Y. L. (2008). Adjusting communication strategies to language proficiency. Prospect, 23(1), $1-9$.

Yu, E. (2012). Does gender, test medium, or attitude matter? Analyzing test takers' responses to technology-mediated speaking tests. Language Testing and Assessment, 1, 1-30. Retrieved from http://www.altaanz.org/uploads/5/9/0/8/5908292/2_yu.pdf

Van Moere, A. (2006). Validity evidence in a university group oral test. Language Testing, 23(4), 411-440. http://dx.doi.org/10.1191/02655322061t336oa 


\section{Copyrights}

Copyright for this article is retained by the author(s), with first publication rights granted to the journal.

This is an open-access article distributed under the terms and conditions of the Creative Commons Attribution license (http://creativecommons.org/licenses/by/3.0/). 